\section{World TB Day — March 24, 2017}

World TB Day is recognized each year on March 24, which commemorates the date in 1882 when Dr. Robert Koch announced his discovery of Mycobacterium tuberculosis, the bacillus that causes tuberculosis (TB). World TB Day provides an opportunity to raise awareness about $\mathrm{TB}$ and the measures needed to tackle this devastating disease. In 2017, for the second year, CDC will join the global Stop TB Partnership in adopting the World TB Day theme "Unite to End TB."

In 2016, a total of 9,287 new TB cases occurred in the United States (incidence of 2.9 cases per 100,000 persons) (1), a decrease from the 2015 case count and incidence. This 2016 provisional case count represents the lowest number of TB cases recorded since reporting began in 1953. However, data suggest that current strategies will not be sufficient to reach the goal of U.S. TB elimination during this century (2).

CDC is committed to eliminating TB in the United States. This will require expanded initiatives, both in the United States and globally. These initiatives must maintain and strengthen existing strategies for diagnosing and treating persons with TB disease and also increase testing and treatment of persons with latent TB infection as outlined in CDC recommendations and the 2016 recommendation from the U.S. Preventive Services Task Force (USPSTF) $(3,4)$. Additional information about World TB Day and CDC's TB elimination activities is available on CDC's TB website (https://www.cdc.gov/tb/worldtbday).

\section{References}

1. Schmit KM, Wansaula Z, Pratt R, Price SF, Langer AJ. TuberculosisUnited States, 2016. MMWR Morb Mortal Wkly Rep 2017;66:289-94.

2. Hill AN, Becerra J, Castro KG. Modelling tuberculosis trends in the USA. Epidemiol Infect 2012;140:1862-72. https://doi.org/10.1017/ S095026881100286X

3. American Thoracic Society; CDC. Targeted tuberculin skin testing and treatment of latent tuberculosis infection. MMWR Recomm Rep 2000;49(No. RR-6).

4. Bibbins-Domingo K, Grossman DC, Curry SJ, et al.; US Preventive Services Task Force. Screening for latent tuberculosis infection in adults: US Preventive Services Task Force recommendation statement. JAMA 2016;316:962-9. https://doi.org/10.1001/jama.2016.11046

\section{Tuberculosis — United States, 2016}

\author{
Kristine M. Schmit, MD ${ }^{1,2}$; Zimy Wansaula, MD ${ }^{1,2}$; Robert Pratt ${ }^{2}$; \\ Sandy F. Price ${ }^{2}$; Adam J. Langer, DVM ${ }^{2}$
}

In 2016, a total of 9,287 new tuberculosis (TB) cases were reported in the United States; this provisional* count represents the lowest number of U.S. TB cases on record and a $2.7 \%$ decrease from 2015 (1). The 2016 TB incidence of 2.9 cases per 100,000 persons represents a slight decrease compared with 2015 (-3.4\%) (Figure). However, epidemiologic modeling demonstrates that if similar slow rates of decline continue, the goal of U.S. TB elimination will not be reached during this century (2). Although current programs to identify and treat active TB disease must be maintained and strengthened, increased measures to identify and treat latent $\mathrm{TB}$ infection (LTBI) among populations at high risk are also needed to accelerate progress toward TB elimination.

*This report is limited to National Tuberculosis Surveillance System data as of February 17, 2017. Updated data will be available in CDC's annual TB surveillance report later this year.

\section{INSIDE}

295 Tuberculosis Among Foreign-Born Persons Diagnosed $\geq 10$ Years After Arrival in the United States, 2010-2015

299 Establishing a Timeline to Discontinue Routine Testing of Asymptomatic Pregnant Women for Zika Virus Infection - American Samoa, 2016-2017

302 Self-Reported Work-Related Injury or Illness Washington, 2011-2014

307 Notes from the Field: Obstetric Tetanus in an Unvaccinated Woman After a Home Birth Delivery - Kentucky, 2016

309 QuickStats

Continuing Education examination available at https://www.cdc.gov/mmwr/cme/conted_info.html\#weekly.

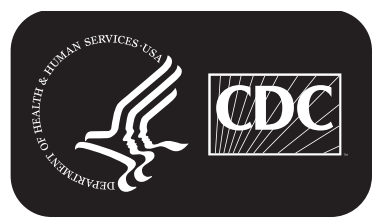

U.S. Department of Health and Human Services Centers for Disease Control and Prevention 
Health departments in the 50 states and District of Columbia (DC) electronically report to $\mathrm{CDC}^{\dagger}$ verified cases of $\mathrm{TB}$ that meet the CDC and Council of State and Territorial Epidemiologists case definition for TB. Reports include demographic and clinical information, as well as medical and social risk factors for TB disease. Persons reported with TB are classified as U.S.-born or foreign-born persons based on established criteria $^{\$}$; race/ethnicity is self-reported. U.S. Census Bureau midyear population estimates provide the denominators used to calculate TB incidence overall (3). The Current Population Survey (https://www.census.gov/programs-surveys/cps.html) provides the population denominators used to calculate TB incidence according to national origin and racial/ethnic group.

State-specific TB incidence in 2016 ranged from 0.2 cases per 100,000 persons in Wyoming to 8.3 in Hawaii (median state incidence $=1.9$ ). Twelve states (Alaska, Arkansas, California, Florida, Georgia, Hawaii, Maryland, Minnesota, New Jersey, New York, North Dakota, and Texas) and DC reported incidence higher than the national incidence (Table 1). As in previous years, four states (California, Florida, New York, and Texas) reported $>500$ cases each in 2016, accounting for $50.9 \%$ of reported cases nationwide.

\footnotetext{
$\dagger^{\dagger}$ https://www.cdc.gov/tb/programs/rvct/instructionmanual.pdf.

$\$$ U.S.-born persons are defined as persons who were born in the United States or a U.S. island area or born abroad to a U.S. citizen parent or parents. All others, including those who have become U.S. citizens through naturalization, are considered to be foreign-born persons.
}

Among 9,287 TB cases reported in 2016, U.S.-born persons accounted for 2,935 (31.6\%) cases, and 6,307 (67.9\%) cases occurred among foreign-born persons; 45 (0.5\%) cases occurred among persons whose national origin was not known (Table 2). TB incidence among U.S.-born persons (1.1 cases per 100,000) decreased 8.4\% from 2015 (Figure). Incidence among foreign-born persons $(14.6$ cases per 100,000$)$ decreased $3.2 \%$ from 2015 , but was approximately 14 times the incidence among U.S.-born persons.

Among U.S.-born persons, TB incidence remained stable among non-Hispanic whites $(0.5$ cases per 100,000$)$ and Asians (2.1), but decreased from 2015 in all other racial/ethnic groups including Hispanics (1.6 [-11.4\%]), non-Hispanic blacks (3.0 [-6.8\%]), American Indian/Alaska Natives (5.0 [-28.8\%]), and Native Hawaiian/Pacific Islanders (9.2 [-27.3\%]) (Table 2). TB incidence has decreased or remained stable since 2013 in all U.S.-born racial/ethnic groups except American Indian/Alaska Natives and Native Hawaiian/Pacific Islanders, which experienced increases during this period before decreasing in 2016.

Among foreign-born persons, the highest TB incidence in 2016 was among Asians $(26.9$ cases per 100,000), followed by non-Hispanic blacks (22.3) and Hispanics (10.0), and most foreign-born racial/ethnic groups have experienced gradual decreases between 2013 and 2016. The top five countries of origin for foreign-born persons reported with TB disease in the United States were Mexico (1,194 cases, $18.9 \%$ of all foreign-born cases), the Philippines (795, 12.6\%), India (593,

The MMWR series of publications is published by the Center for Surveillance, Epidemiology, and Laboratory Services, Centers for Disease Control and Prevention (CDC), U.S. Department of Health and Human Services, Atlanta, GA 30329-4027.

Suggested citation: [Author names; first three, then et al., if more than six.] [Report title]. MMWR Morb Mortal Wkly Rep 2017;66:[inclusive page numbers].

\section{Centers for Disease Control and Prevention}

Anne Schuchat, MD, Acting Director

Patricia M. Griffin, MD, Acting Associate Director for Science

Joanne Cono, MD, ScM, Director, Office of Science Quality

Chesley L. Richards, MD, MPH, Deputy Director for Public Health Scientific Services

Michael F. Iademarco, MD, MPH, Director, Center for Surveillance, Epidemiology, and Laboratory Services

\section{MMWR Editorial and Production Staff (Weekly)}

Sonja A. Rasmussen, MD, MS, Editor-in-Chief

Charlotte K. Kent, PhD, MPH, Executive Editor Jacqueline Gindler, MD, Editor

Teresa F. Rutledge, Managing Editor

Douglas W. Weatherwax, Lead Technical Writer-Editor

Stacy A. Benton, Soumya Dunworth, PhD, Teresa M. Hood, MS, Technical Writer-Editors

MMWR Editorial Board

Timothy F. Jones, MD, Chairman

Matthew L. Boulton, MD, MPH Virginia A. Caine, MD

Katherine Lyon Daniel, PhD

Jonathan E. Fielding, MD, MPH, MBA

David W. Fleming, MD

\author{
William E. Halperin, MD, DrPH, MPH \\ King K. Holmes, MD, PhD \\ Robin Ikeda, MD, MPH \\ Rima F. Khabbaz, MD \\ Phyllis Meadows, PhD, MSN, RN \\ Jewel Mullen, MD, MPH, MPA
}

Martha F. Boyd, Lead Visual Information Specialist

Maureen A. Leahy, Julia C. Martinroe, Stephen R. Spriggs, Tong Yang, Visual Information Specialists

Quang M. Doan, MBA, Phyllis H. King,

Terraye M. Starr, Moua Yang,

Information Technology Specialists

\author{
Jeff Niederdeppe, $\mathrm{PhD}$ \\ Patricia Quinlisk, MD, MPH \\ Patrick L. Remington, MD, MPH \\ Carlos Roig, MS, MA \\ William L. Roper, MD, MPH \\ William Schaffner, MD
}


TABLE 1. Tuberculosis (TB) case counts and incidence with annual percent changes, by U.S. Census division and state/district - United States and the District of Columbia, 2015 and 2016

\begin{tabular}{|c|c|c|c|c|c|c|}
\hline \multirow[b]{2}{*}{$\begin{array}{l}\text { Census } \\
\text { division/state }\end{array}$} & \multicolumn{3}{|c|}{ Case count* } & \multicolumn{3}{|c|}{ Incidence } \\
\hline & 2015 & 2016 & $\begin{array}{c}\% \\
\text { Change }\end{array}$ & 2015 & 2016 & $\begin{array}{c}\% \\
\text { Change }^{\dagger}\end{array}$ \\
\hline \multicolumn{7}{|c|}{ Division 1: New England } \\
\hline Connecticut & 70 & 52 & -25.7 & 2.0 & 1.5 & -25.5 \\
\hline Maine & 18 & 23 & 27.8 & 1.4 & 1.7 & 27.6 \\
\hline Massachusetts & 192 & 190 & -1.0 & 2.8 & 2.8 & -1.4 \\
\hline New Hampshire & 13 & 15 & 15.4 & 1.0 & 1.1 & 15.0 \\
\hline Rhode Island & 30 & 12 & -60.0 & 2.8 & 1.1 & -60.0 \\
\hline Vermont & 7 & 5 & -28.6 & 1.1 & 0.8 & -28.4 \\
\hline Total & 330 & 297 & -10.0 & 2.2 & 2.0 & -10.2 \\
\hline \multicolumn{7}{|c|}{ Division 2: Middle Atlantic } \\
\hline New Jersey & 326 & 294 & -9.8 & 3.6 & 3.3 & -9.9 \\
\hline New York & 763 & 768 & 0.7 & 3.9 & 3.9 & 0.7 \\
\hline Pennsylvania & 200 & 174 & -13.0 & 1.6 & 1.4 & -12.9 \\
\hline Total & 1289 & 1236 & -4.1 & 3.1 & 3.0 & -4.1 \\
\hline \multicolumn{7}{|c|}{ Division 3: East North Central } \\
\hline Illinois & 343 & 342 & -0.3 & 2.7 & 2.7 & 0.0 \\
\hline Indiana & 116 & 109 & -6.0 & 1.8 & 1.6 & -6.3 \\
\hline Michigan & 131 & 133 & 1.5 & 1.3 & 1.3 & 1.4 \\
\hline Ohio & 143 & 141 & -1.4 & 1.2 & 1.2 & -1.5 \\
\hline Wisconsin & 69 & 40 & -42.0 & 1.2 & 0.7 & -42.1 \\
\hline Total & 802 & 765 & -4.6 & 1.7 & 1.6 & -4.6 \\
\hline \multicolumn{7}{|c|}{ Division 4: West North Central } \\
\hline lowa & 38 & 48 & 26.3 & 1.2 & 1.5 & 25.8 \\
\hline Kansas & 36 & 39 & 8.3 & 1.2 & 1.3 & 8.3 \\
\hline Minnesota & 150 & 168 & 12.0 & 2.7 & 3.0 & 11.2 \\
\hline Missouri & 92 & 101 & 9.8 & 1.5 & 1.7 & 9.5 \\
\hline Nebraska & 33 & 28 & -15.2 & 1.7 & 1.5 & -15.7 \\
\hline North Dakota & 9 & 22 & 144.4 & 1.2 & 2.9 & 144.1 \\
\hline South Dakota & 17 & 12 & -29.4 & 2.0 & 1.4 & -30.0 \\
\hline Total & 375 & 418 & 11.5 & 1.8 & 2.0 & 11.0 \\
\hline \multicolumn{7}{|c|}{ Division 5: South Atlantic } \\
\hline Delaware & 22 & 16 & -27.3 & 2.3 & 1.7 & -27.9 \\
\hline District of Columbia & 33 & 25 & -24.2 & 4.9 & 3.7 & -25.4 \\
\hline Florida & 602 & 639 & 6.1 & 3.0 & 3.1 & 4.3 \\
\hline Georgia & 320 & 302 & -5.6 & 3.1 & 2.9 & -6.6 \\
\hline Maryland & 176 & 220 & 25.0 & 2.9 & 3.7 & 24.6 \\
\hline North Carolina & 199 & 220 & 10.6 & 2.0 & 2.2 & 9.3 \\
\hline South Carolina & 104 & 103 & -1.0 & 2.1 & 2.1 & -2.3 \\
\hline Virginia & 212 & 205 & -3.3 & 2.5 & 2.4 & -3.8 \\
\hline West Virginia & 10 & 14 & 40.0 & 0.5 & 0.8 & 40.8 \\
\hline Total & 1678 & 1744 & 3.9 & 2.7 & 2.7 & 2.7 \\
\hline
\end{tabular}

9.4\%), Vietnam (496, 7.9\%), and China (383, 6.1\%). Cases in persons born in these countries accounted for $54.9 \%$ of all cases among foreign-born persons.

HIV status was known for $86.7 \%$ of TB cases reported in 2016; among these patients, $5.8 \%$ had documented HIV coinfection. Living in congregate settings such as shelters, longterm care facilities, and correctional facilities is a known risk factor for TB exposure (4), and complete data on these risk factors were available for $>93 \%$ of cases. Among these, $4.6 \%$ of patients reported having experienced homelessness in the
TABLE 1. (Continued) Tuberculosis (TB) case counts and incidence with annual percent changes, by U.S. Census division and state/ district - United States and the District of Columbia, 2015 and 2016

\begin{tabular}{|c|c|c|c|c|c|c|}
\hline \multirow[b]{2}{*}{$\begin{array}{l}\text { Census } \\
\text { division/state }\end{array}$} & \multicolumn{3}{|c|}{ Case count* } & \multicolumn{3}{|c|}{ Incidence } \\
\hline & 2015 & 2016 & $\begin{array}{c}\% \\
\text { Change }\end{array}$ & 2015 & 2016 & $\begin{array}{c}\% \\
\text { Change }^{\dagger}\end{array}$ \\
\hline \multicolumn{7}{|c|}{ Division 6: East South Central } \\
\hline Alabama & 119 & 112 & -5.9 & 2.5 & 2.3 & -6.1 \\
\hline Kentucky & 67 & 91 & 35.8 & 1.5 & 2.1 & 35.4 \\
\hline Mississippi & 74 & 61 & -17.6 & 2.5 & 2.0 & -17.5 \\
\hline Tennessee & 131 & 103 & -21.4 & 2.0 & 1.5 & -22.0 \\
\hline Total & 391 & 367 & -6.1 & 2.1 & 1.9 & -6.5 \\
\hline \multicolumn{7}{|c|}{ Division 7: West South Central } \\
\hline Arkansas & 90 & 91 & 1.1 & 3.0 & 3.0 & 0.8 \\
\hline Louisiana & 119 & 127 & 6.7 & 2.5 & 2.7 & 6.4 \\
\hline Oklahoma & 67 & 78 & 16.4 & 1.7 & 2.0 & 15.9 \\
\hline Texas & 1333 & 1250 & -6.2 & 4.9 & 4.5 & -7.7 \\
\hline Total & 1609 & 1546 & -3.9 & 4.1 & 3.9 & -5.1 \\
\hline \multicolumn{7}{|c|}{ Division 8: Mountain } \\
\hline Arizona & 198 & 188 & -5.1 & 2.9 & 2.7 & -6.6 \\
\hline Colorado & 73 & 64 & -12.3 & 1.3 & 1.2 & -13.8 \\
\hline Idaho & 11 & 18 & 63.6 & 0.7 & 1.1 & 60.7 \\
\hline Montana & 9 & 4 & -55.6 & 0.9 & 0.4 & -56.0 \\
\hline Nevada & 85 & 56 & -34.1 & 2.9 & 1.9 & -35.4 \\
\hline New Mexico & 47 & 39 & -17.0 & 2.3 & 1.9 & -17.0 \\
\hline Utah & 37 & 20 & -45.9 & 1.2 & 0.7 & -47.0 \\
\hline Wyoming & 4 & 1 & -75.0 & 0.7 & 0.2 & -75.0 \\
\hline Total & 464 & 390 & -15.9 & 2.0 & 1.6 & -17.2 \\
\hline \multicolumn{7}{|c|}{ Division 9: Pacific } \\
\hline Alaska & 68 & 57 & -16.2 & 9.2 & 7.7 & -16.6 \\
\hline California & 2130 & 2073 & -2.7 & 5.5 & 5.3 & -3.3 \\
\hline Hawaii & 127 & 119 & -6.3 & 8.9 & 8.3 & -6.5 \\
\hline Oregon & 76 & 70 & -7.9 & 1.9 & 1.7 & -9.4 \\
\hline Washington & 207 & 205 & -1.0 & 2.9 & 2.8 & -2.7 \\
\hline Total & 2608 & 2524 & -3.2 & 5.0 & 4.8 & -4.1 \\
\hline United States & 9546 & 9287 & -2.7 & 3.0 & 2.9 & -3.4 \\
\hline
\end{tabular}

* Case counts based on data from the National Tuberculosis Surveillance System as of February 17, 2017. U.S. Census Bureau midyear population estimates provide the denominators used to calculate TB incidence.

+ Percentage change in incidence is calculated on the basis of unrounded incidence for 2015 and 2016.

year preceding diagnosis. In addition, $1.8 \%$ were reported as residing in a long-term care facility, and $3.5 \%$ were reported as being confined in a correctional facility at the time of diagnosis.

The most recent year for which complete drug-susceptibility data are available is 2015; the data include test results for $98.7 \%$ of culture-confirmed TB cases. In 2015, 88 cases of multidrugresistant $\mathrm{TB}$ occurred; multidrug-resistant $\mathrm{TB}$ accounted for $0.4 \%$ and $1.2 \%$ of culture-confirmed TB cases among U.S.born and foreign-born persons, respectively. Among the 88 multidrug-resistant TB cases, 72 (81.8\%) occurred in persons

\footnotetext{
Multidrug-resistant tuberculosis (TB) is defined by the World Health Organization as a case of TB in a person with a Mycobacterium tuberculosis isolate resistant to at least isoniazid and rifampin.
} 
Morbidity and Mortality Weekly Report

TABLE 2. Tuberculosis (TB) case counts and incidence, ${ }^{*}$ by national origin and race/ ethnicity — United States, 2013-2016 ${ }^{\dagger}$

\begin{tabular}{|c|c|c|c|c|}
\hline \multirow[b]{2}{*}{ U.S. population group } & \multicolumn{4}{|c|}{ Case count (incidence) } \\
\hline & 2013 & 2014 & 2015 & 2016 \\
\hline \multicolumn{5}{|l|}{ U.S.-born ${ }^{\S}$} \\
\hline Hispanic & $650(1.8)$ & $651(1.8)$ & $657(1.8)$ & $599(1.6)$ \\
\hline White, non-Hispanic & $1,092(0.6)$ & $970(0.5)$ & $987(0.5)$ & $911(0.5)$ \\
\hline Black, non-Hispanic & $1,251(3.6)$ & $1,186(3.4)$ & $1,139(3.3)$ & $1,062(3.0)$ \\
\hline Asian & $151(2.4)$ & $137(2.1)$ & $136(2.1)$ & $145(2.1)$ \\
\hline American Indian/Alaska Native & $122(5.6)$ & $114(5.1)$ & $144(7.0)$ & $108(5.0)$ \\
\hline Native Hawaiian/Pacific Islander & $45(6.3)$ & $83(12.4)$ & $88(12.7)$ & $67(9.2)$ \\
\hline Multiple or unknown race/ ethnicity & $44($-9) & $37($ - $)$ & $35(-9)$ & $43(-9)$ \\
\hline Total U.S.-born & $3,355(1.2)$ & $3,178(1.2)$ & $3,186(1.2)$ & $2,935(1.1)$ \\
\hline \multicolumn{5}{|l|}{ Foreign-born } \\
\hline Hispanic & $2,033(11.1)$ & $2,093(11.2)$ & $2,033(10.4)$ & $1,979(10.0)$ \\
\hline White, non-Hispanic & $323(4.2)$ & $279(3.6)$ & $252(3.3)$ & $293(3.9)$ \\
\hline Black, non-Hispanic & $835(24.5)$ & $828(23.6)$ & $852(23.0)$ & $898(22.3)$ \\
\hline Asian & $2,850(29.0)$ & $2,920(29.3)$ & $3,089(29.0)$ & $3,023(26.9)$ \\
\hline American Indian/Alaska Native & $2(3.0)$ & - ${ }^{* *}$ & $1(1.9)$ & $2(5.8)$ \\
\hline Native Hawaiian/Pacific Islander & $17(6.7)$ & $8(3.6)$ & $14(4.3)$ & $12(3.3)$ \\
\hline Multiple or unknown race/ ethnicity & 125 (一?) & $92($ - $)$ & 111 (一9) & $100(-9)$ \\
\hline Total foreign-born & $6,185(15.6)$ & $6,220(15.4)$ & $6,352(15.1)$ & $6,307(14.6)$ \\
\hline Unknown national origin & 9 (一") & 5 (-9) & $8(-9)$ & 45 (-9) \\
\hline Total & $9,549(3.0)$ & $9,403(3.0)$ & $9,546(3.0)$ & $9,287(2.9)$ \\
\hline
\end{tabular}

* Incidence calculated per 100,000 persons.

† Case counts based on data from the National Tuberculosis Surveillance System as of February 17, 2017. The Current Population Survey (https://www.census.gov/ programs-surveys/cps.html) provides the population denominators used to calculate TB incidence according to national origin and racial/ ethnic group.

$\S$ U.S.-born persons were born in the United States or a U.S. island area or born abroad to a U.S. citizen parent or parents. All others, including naturalized U.S. citizens, are considered to be foreign-born persons.

I Incidence was not calculated for these categories.

** No cases for foreign-born American Indian/Alaska Native population occurred in 2014.

FIGURE. Tuberculosis (TB) incidence overall and among U.S.-born and foreign-born persons* — United States, $2002-2016$

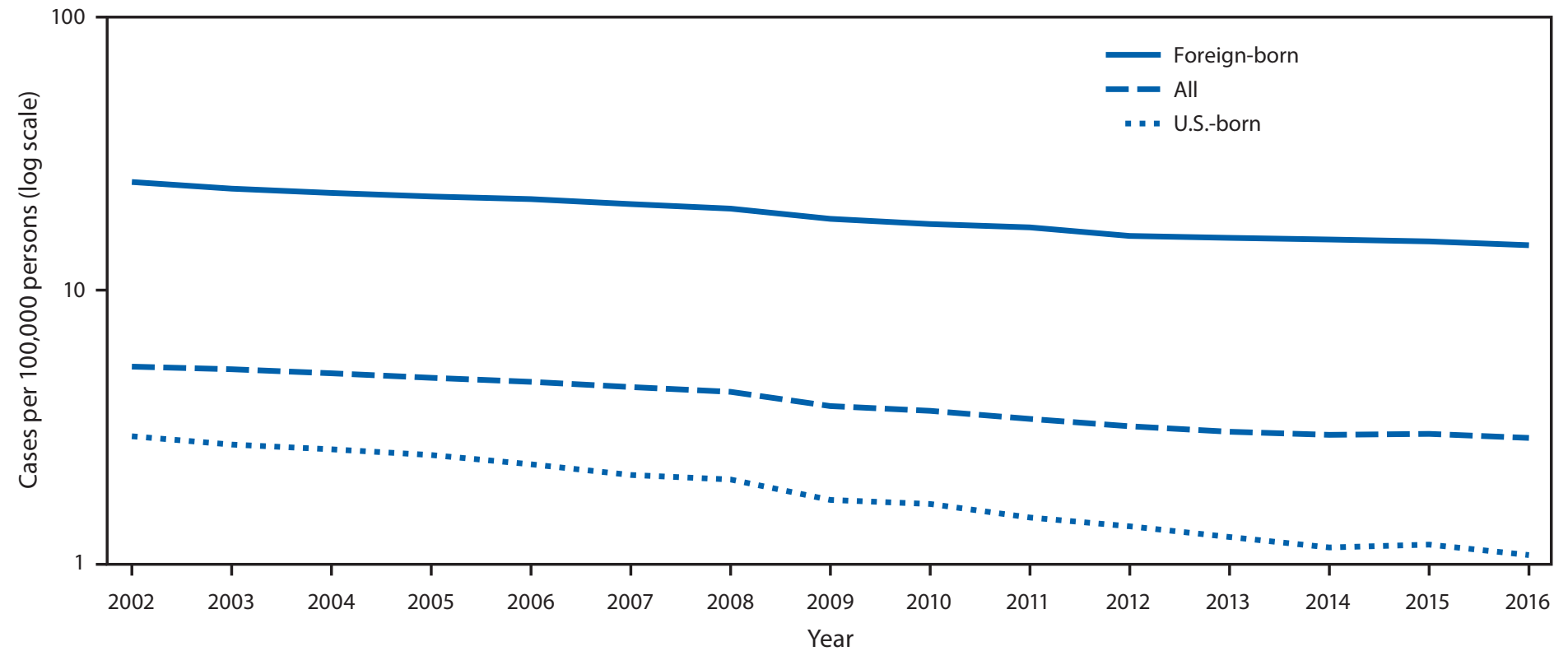

* U.S.-born persons are those persons who were born in the United States or a U.S. island area or were born abroad to a U.S. citizen parent or parents. All others, including naturalized U.S. citizens, are considered foreign-born persons. 


\section{Summary}

What is already known about this topic?

An annual decline in the number of cases and incidence of tuberculosis (TB) in the United States was found beginning in 1993 and continuing until 2015, when the case count increased and the incidence remained the same as the previous year.

What is added by this report?

Provisional data for 2016 indicate a decreased TB case count and incidence compared with 2015.

What are the implications for public health practice?

Current strategies are effective in controlling TB, but not sufficient to promote progress toward the goal of eliminating TB in the United States. Current TB control priorities remain important to prevent a resurgence of TB, but expanded measures and new strategies are needed to achieve TB elimination. Targeted testing and treatment of latent TB infection in populations at high risk for TB are key strategies for lowering incidence and moving toward elimination.

with no reported prior history of TB disease. In 2015, one case of extensively drug-resistant $\mathrm{TB}^{* *}$ was reported.

\section{Discussion}

Provisional data for 2016 demonstrate a slight decline in both TB case count and incidence in the United States compared with 2015. However, previously published epidemiologic modeling suggests that maintaining similar rates of decline in the future will not be sufficient to achieve TB elimination in the United States during this century (2). Current TB control priorities, including early identification of $\mathrm{TB}$ cases, prompt institution of appropriate treatment, and identification of exposed contacts remain critical to preventing a resurgence of TB; to achieve TB elimination, expanded measures and new strategies are needed. Epidemiologic models demonstrate that identifying and treating persons with LTBI (a condition that occurs when a person is infected with Mycobacterium tuberculosis without signs and symptoms, or radiographic or bacteriologic evidence of TB disease) is critical to accomplishing the goal of TB elimination (2). This strategy is consistent with CDC recommendations as well as 2016 recommendations from the U.S. Preventive Services Task Force (USPSTF) to screen for LTBI with tests such as the tuberculin skin test or interferon-gamma release assay in populations that are at increased risk for TB $(4,5)$. The USPSTF characterizes populations at increased risk as those persons who were born in, or

\footnotetext{
** Extensively drug-resistant TB is defined by the World Health Organization as a case of TB in a person with a Mycobacterium tuberculosis isolate with resistance to at least isoniazid and rifampin among first-line anti-TB drugs, resistance to any fluoroquinolone (e.g., ciprofloxacin or ofloxacin), and resistance to at least one of three second-line injectable drugs (i.e., amikacin, capreomycin, or kanamycin).
}

formerly resided in, countries with increased TB prevalence as defined by the World Health Organization (WHO) (G); and persons who currently live in, or have lived in high-risk congregate settings such as homeless shelters, correctional facilities, and long-term care facilities.

In 2016, four of the top five countries of origin for foreignborn persons reported with TB disease were considered high TB burden countries by WHO (China, India, Philippines, Vietnam), and accounted for $36 \%$ of incident TB cases among foreign-born persons in the United States ( 6 ). Because approximately $90 \%$ of TB cases in foreign-born persons in the United States are attributable to reactivation of LTBI, targeted testing for and treatment of LTBI among foreign-born persons from countries with high TB prevalence could be an effective strategy to decrease TB incidence ( 7 ). The current recommendation from the USPSTF to test persons at increased risk regardless of length of time in the United States is in keeping with evidence that reactivation of LTBI remains a substantial concern, even in foreign-born persons who have lived in the United States for many years $(8,9)$.

Workers in high-risk congregate settings are also at increased risk for TB and should be included as part of a targeted testing and treatment approach (4). Other persons at risk for TB infection or for progression from LTBI to TB disease who should also be included in this strategy include close contacts of infectious TB patients, persons with immunosuppression, persons with other medical conditions (e.g., diabetes mellitus, chronic renal failure, or silicosis) associated with progression from LTBI to TB disease, and persons with fibrotic changes on a chest radiograph suggestive of inactive TB disease (4).

The findings in this report are subject to at least two limitations. First, this analysis is limited to reported provisional case counts and incidence rates for 2016. Second, incidence rates are calculated based on estimated population denominators for 2016.

Although TB case counts and incidence are decreasing in the United States, progress is insufficient to achieve in this century the goal of TB elimination. Measures to diagnose and treat active TB disease must continue, and new strategies aimed at accelerating progress toward TB elimination in the United States, such as targeted testing for and treatment of LTBI, should also be employed. Expanded partnerships with health care providers outside of the public health sector will be important in effectively implementing such a strategy.

\section{Acknowledgments}

State, local, tribal, and territorial health department personnel; Cynthia Adams, Lori Armstrong, Michael Chen, Glenda Newell, Stacey Parker, Jeanette Roberts, Clarisse Tsang, and Katrina Williams, National Center for HIV/AIDS, Viral Hepatitis, STD, and TB Prevention, CDC. 
${ }^{1}$ Epidemic Intelligence Service, CDC; ${ }^{2}$ Division of Tuberculosis Elimination, National Center for HIV/AIDS, Viral Hepatitis, STD, and TB Prevention, CDC.

Corresponding authors: Kristine M. Schmit, kmschmit@cdc.gov, 404-639-1694; Zimy Wansaula, zwansaula@cdc.gov, 404-718-5456.

\section{References}

1. CDC. Reported tuberculosis in the United States, 2015. Atlanta, GA: US Department of Health and Human Services, CDC; 2016. https:// www.cdc.gov/tb/statistics/reports/2015/default.htm

2. Hill AN, Becerra J, Castro KG. Modelling tuberculosis trends in the USA. Epidemiol Infect 2012;140:1862-72. https://doi.org/10.1017/ S095026881100286X

3. US Census Bureau. Population, population change, and estimated components of population change: April 1, 2010 to July 1, 2016 (NSTEST2016-alldata). Washington, DC: US Census Bureau; 2017. https:// www.census.gov/data/datasets/2016/demo/popest/nation-total.html
4. American Thoracic Society. CDC. Targeted tuberculin skin testing and treatment of latent tuberculosis infection. MMWR Recomm Rep 2000;49(No. RR-6).

5. Bibbins-Domingo K, Grossman DC, Curry SJ, et al.; US Preventive Services Task Force. Screening for latent tuberculosis infection in adults: US Preventive Services Task Force recommendation statement. JAMA 2016;316:962-9. https://doi.org/10.1001/jama.2016.11046

6. World Health Organization. Global Tuberculosis Report 2016. Geneva, Switzerland: World Health Organization; 2017. http://www.who.int/tb/ publications/global_report/gtbr2016_annex2.pdf?ua=1

7. Yuen CM, Kammerer JS, Marks K, Navin TR, France AM. Recent transmission of tuberculosis-United States, 2011-2014. PLoS One 2016;11:e0153728. https://doi.org/10.1371/journal.pone.0153728

8. Cain KP, Benoit SR, Winston CA, Mac Kenzie WR. Tuberculosis among foreign-born persons in the United States. JAMA 2008;300:405-12. https://doi.org/10.1001/jama.300.4.405

9. Tsang CA, Langer AJ, Navin TR, Armstrong LR. Tuberculosis among foreign-born persons diagnosed $\geq 10$ years after arrival in the United States, 2010-2015. MMWR Morb Mortal Wkly Rep 2017;66:295-8. 